\title{
Determination of Aflatoxins in Spices and Dried Fruits
}

\author{
N. Zahra ${ }^{*}$, M. Khan' ${ }^{2}$ Z. Mehmood ${ }^{2}$, M. K. Saeed ${ }^{1}$, I. Kalim ${ }^{1}$, I. Ahmad ${ }^{1}$, K. A. Malik ${ }^{2}$ \\ ${ }^{1}$ Pakistan Council of Scientific and Industrial Research Laboratories Complex, Ferozepur Road, \\ Lahore, 54600, Pakistan \\ ${ }^{2}$ Department of Biological Sciences, Forman Christian College, Lahore, Pakistan
}

Received 20 June 2018, accepted in final revised form 30 June 2018

\begin{abstract}
The purpose of current study was to estimate the incidence of total aflatoxins $\left(B_{1}+B_{2}+G_{1}+G_{2}\right)$ in unpack spices and dried fruits. A total of 90 samples included red chillies, black pepper, figs and dried apricots were picked from shops/markets situated in Lahore - Pakistan and were analyzed by using thin layer chromatography (TLC). The results showed that aflatoxin $\mathrm{B}_{1}$ was detected in $24(26 \%)$ samples. The results obtained were ranging between $23.99-97.42 \mu \mathrm{gkg}^{-1}$ in spices, $47.68-75.78 \mu \mathrm{gkg}^{-1}$ in black pepper, $6.72-14.43 \mu \mathrm{gkg}^{-1}$ in figs while $13.2 \mu \mathrm{gkg}^{-1}$ of aflatoxin $\mathrm{B}_{1}$ was present in apricot sample. $39.28 \%, 18.18 \%, 5.0 \%$ and $40 \%$ samples of red chilli, black pepper, dried apricots and figs were found contaminated with aflatoxins respectively. Among contaminated samples $32.14 \%, 13.63 \%, 5.0 \%$ and $15 \%$ samples of red chilli, black pepper, dried apricots and figs, respectively were found contaminated with aflatoxins beyond permissible limits. Furthermore, $17.77 \%$ i.e. $n=16$ of the positive samples contained Aflatoxin $B_{1}$ level more than the permitted limit for entire aflatoxins as lay down by regulatory authority. From the study, it was concluded that a continuous and strict national monitoring plan is needed to improve quality and safety of spices and dried fruits supply in Pakistan.
\end{abstract}

Keywords: Aflatoxins; Contamination; Spices; Dried fruits; TLC.

(C) 2018 JSR Publications. ISSN: 2070-0237 (Print); 2070-0245 (Online). All rights reserved. doi: http://dx.doi.org/10.3329/jsr.v10i3.37075 $\quad$ J. Sci. Res. 10 (3), 315-321 (2018)

\section{Introduction}

Spices and dried fruits have become an essential part of food. Healthy life style needs provision of safe and good quality food. But unfortunately food can be easily contaminated through the environment. Harmful substances can gain entry in plants due to unpleasant external conditions. Plants naturally may have nontoxic and toxic substances in their various parts. Microorganisms are ubiquitously present in surroundings. Microorganisms can either be nonpoisonous or poisonous depending upon circumstances. Fungi are imperative plant pathogens which may cause production of so many malevolent

\footnotetext{
*Corresponding author: naseem.zahra1981@gmail.com
} 
metabolites [1]. Secondary metabolites named "Mycotoxins" are produced when filamentous fungus undergoes enzymatic or chemical reaction. These mycotoxins are very toxic and hazardous to animals, plants and human beings as well. Mycotoxin contamination causes huge damage to crops each year [2].

Aflatoxins are familiar mycotoxins which may badly affect all food entities. Warm and humid regions of the world are favorable environments for aflatoxins growth. According to International Agency for Research on Cancer, aflatoxins are included in class 1A human carcinogens [3]. Aflatoxin exposure may cause impaired growth, decrease immunity of body and its severity may cause liver cancer. Aflatoxin $\mathrm{B}_{1}$ and $\mathrm{B}_{2}$ are produced by Aspergillus parasiticus and Aspergillus flavus [4] while Aspergillus parasiticus and Aspergillus nomius produce aflatoxin $\mathrm{G}_{1}$ and $\mathrm{G}_{2}$ [5].

Contamination of aflatoxins in various food commodities is of prime concern as occurrence of aflatoxins a big threat to food security and quality. Aflatoxins contamination badly affect agriculture sector. Consequently, it may have bad impacts on main four pillars of food protection i.e. accessibility, availability, stability and utilization. Spices and dried fruits are more at danger to attack by aflatoxins due to unhygienic and bad storage conditions. Poor pre- and post-harvest conditions may cause contamination of spices and dried fruits. Careful drying, handling, transportation and storage are needed to avoid aflatoxin contamination in food commodities [6].

In one study, it was reported that spices imported from India were contaminated with aflatoxin $\mathrm{B}_{1}$ within range of $1.2-968.3 \mu \mathrm{gkg}^{-1}$. World Health Organization set permissible levels for total aflatoxins in spices i.e. $30 \mu \mathrm{gkg}^{-1}$ [7].

Aflatoxin contamination in various crops may result in economy losses as well as severe deterioration of human health. Scientists around the world are working on advanced technologies in order to reduce aflatoxins contamination during pre- and postharvest conditions [8].

To investigate the current contamination scenario in Lahore, various samples of spices and dried fruits were checked for aflatoxin contamination.

\section{Materials and Method}

\subsection{Collection of samples}

For the present study, total 90 samples of black peppers (Piper nigrum), red chillies (Capsicum annuum), dried apricots (Prunusarmeniaca) and figs (Ficuscarica) were obtained from different shops/markets in Lahore like Barkat Market, BhattaChowk, Gharishaw Market, Ichhra Market, Jaffarabad Market, Market near Lahore Motorway, Samanabad, Township Market and shops at Wahdat Road.

\subsection{Reagents and chemicals}

Total Aflatoxins ( $\mathrm{B}_{1}, \mathrm{~B}_{2}, \mathrm{G}_{1}$ and $\mathrm{G} 2$ ) standard were purchased from the Romer Lab, Singapore and TLC plates were purchased from Merck, USA. Acetone, acetonitrile 
anhydrous ether, benzene, chloroform and other chemicals used for present work were of analytical grade.

\subsection{Grinding of sample}

In order to obtain homogenous samples AOAC method (number: 977.16) was used [9]. $500 \mathrm{~g}$ of each sample was collected from market and carefully and uniformly mixed for 10-15 min. A representative sample for analysis was obtained by grinding whole sample in grinding mill. $50 \mathrm{~g}$ of every sample was used for AFs analysis in collected samples. All grinded samples were stored in air tight polyethylene bags.

\subsection{Aflatoxin extraction}

$50 \mathrm{~g}$ of grinded sample was taken in $500 \mathrm{~mL}$ conical flask. $25 \mathrm{~mL}$ of water, $25 \mathrm{~g}$ diatomaceous earth and $150 \mathrm{~mL}$ chloroform were added. The whole mixture in flask was mixed thoroughly for $30 \mathrm{~min}$ on wrist shaker. The mixture was filtered by using Whatmann No. 1 filter paper and $50 \mathrm{~mL}$ of mixture solution (chloroform) was obtained in a beaker. This sample solution was evaporated on water bath at $60^{\circ} \mathrm{C}[10]$.

\subsection{Thin Layer Chromatography (TLC)}

Spotting of sample 2.0, 3.5, 5.0, 6.5, 10, 15 and $25 \mu \mathrm{L}$ was done on TLC plate (nearly 1.5 $\mathrm{cm}$ from the base) by using micro syringe. Similarly, spotting of 1, 2.5 and $5 \mu \mathrm{L}$ standard was done. After spotting, the plate was paced in first tank containing anhydrous diethyl ether. After developing plate in first tank, the plate was dried and was placed in tank containing acetone-chloroform $(1: 9, \mathrm{v} / \mathrm{v})$. Depending upon $\mathrm{R}_{\mathrm{f}}$ values, the ratio adjustment was done. The plate was observed under UV light $(365 \mathrm{~nm})$ for checking the presence or absence of aflatoxins. The concentration of aflatoxins depends on the intensity of fluorescence. $R_{\mathrm{f}}$ values and sample color is analogous to aflatoxin standard.

\subsection{Detection and quantification}

Fluorescent intensities of standards spots and sample spots showing aflatoxins were compared. The amount of aflatoxins in spices and dried fruits samples was determined in $\mu \mathrm{gkg}^{-1}$ using subsequent formula:

Aflatoxins in $\mu \mathrm{g} / \mathrm{kg}=\frac{\mathrm{S} \times \mathrm{Y} \times \mathrm{V}}{\mathrm{Z} \times \mathrm{W}}$

Where,

$\mathrm{S}$ : Volume of aflatoxin standard in $\mathrm{mL}$ of correspondent intensity to $\mathrm{Z}=\mathrm{mL}$ of sample

Y: Aflatoxin standard concentration in $\mathrm{mg} / \mathrm{mL}$

$\mathrm{V}$ : Volume required diluting final extract in $\mathrm{mL}$

$\mathrm{W}$ : Effective weight in grams contained in final sample extract

$\mathrm{Z}$ : Volume of sample extract in $\mathrm{mL}$ required to confer fluorescence intensity analogous to that of $\mathrm{S}=\mathrm{mL}$ of aflatoxins standard 
The obtained results were analyzed statistically. Standard deviation, Mean, Max and Min were calculated.

\section{Results and Discussion}

\subsection{Screening of samples}

Different food entities were collected from Lahore city and were subjected to aflatoxins analysis by thin layer chromatography (TLC) for quantitative and qualitative analysis of aflatoxins. It was observed that 24 samples of spices and dried fruits showed Aflatoxin $\mathrm{B}_{1}$ presence, however 66 samples were not contaminated with aflatoxins (Table1).

Table1.Screening of food samples for aflatoxin done by TLC.

\begin{tabular}{|c|c|c|c|c|c|c|c|c|}
\hline $\mathrm{AF}$ & Sample & $\begin{array}{l}\text { No. of } \\
\text { Samples }\end{array}$ & $\begin{array}{l}\text { No. of } \\
\text { Contaminated } \\
\text { Samples }\end{array}$ & $\begin{array}{l}\text { No. of Non } \\
\text { Contaminated } \\
\text { Samples }\end{array}$ & $\begin{array}{l}\text { Contamination } \\
(\%)\end{array}$ & $\begin{array}{l}\text { Max } \\
\mu \mathrm{gkg}^{-1}\end{array}$ & $\begin{array}{l}\text { Min } \\
\mu \mathrm{gkg}^{-1}\end{array}$ & $\begin{array}{l}\text { Permissible } \\
\text { limit }\end{array}$ \\
\hline \multirow[t]{8}{*}{$\mathrm{B}_{1}$} & Figs & 20 & 8 & 12 & $40 \%$ & 14.43 & 6.72 & $10 \mu \mathrm{gkg}^{-1}$ \\
\hline & & & & & & & & USFDA \\
\hline & Apricot & 20 & 1 & 19 & $5 \%$ & 13.2 & ND & $10 \mu \mathrm{gkg}^{-1}$ \\
\hline & & & & & & & & USFDA \\
\hline & Black & 22 & 4 & 18 & $18 \%$ & 75.78 & 47.68 & $10 \mu \mathrm{gkg}^{-1}$ \\
\hline & Pepper & & & & & & & USFDA \\
\hline & Red & 28 & 11 & 17 & $39 \%$ & 97.42 & 23.99 & $50 \mu \mathrm{gkg}^{-1}$ \\
\hline & Chili & & & & & & & [11] \\
\hline
\end{tabular}

$* \mathrm{ND}=$ Not Detected

Aflatoxin $\left(\mathrm{AFB}_{1}\right)$ was found in 24 samples collected from various areas of Lahore, Pakistan but other Aflatoxins $B_{2}, G_{1}$ and $G_{2}$ were absent in all collected food samples. Samples of red chillies, black pepper, figs and dried apricots were contaminated with aflatoxin $\mathrm{B}_{1}$ within the range 6.72- $97.42 \mu \mathrm{gkg}^{-1}$.

Different tolerance limits for aflatoxins were set by USFDA (United State Food and Drug Administration), i.e. $10 \mu \mathrm{gkg}^{-1}$ in dried fruits, black pepper and in further processed products [12]. 17 samples of red chillies were from aflatoxins contamination. 4 samples of ground black pepper contained aflatoxinsin the range of $47.68-75.78 \mu \mathrm{gkg}^{-1}$ and among aflatoxin contaminated samples, 3 were found beyond permissible levels while 1 was within the range, as placed by UNCTAD (United Nation Conference on Trade and Development) for human consumption i.e. below $50 \mu \mathrm{gkg}^{-1}$ for red chillies. According to UNCTAD, 1996, permissible level of aflatoxins in red chillies is $50 \mu \mathrm{gkg}^{-1}$ [13].

17 samples of red chilli out of 28, 18 samples of black pepper out of 22, 19 samples of dried apricots out of 20 and 12 samples of figs out of 20 were found uncontaminated with aflatoxins. The maximum contamination beyond permissible limits i.e. $32.14 \%$ was found in red chillies as compared to other food commodities. However, overall \% contamination of $39.28 \%, 18.18 \%, 5 \%$ and $40 \%$ were found in red chillies, black pepper, 
dried apricots and figs respectively. Maximum number of figs was found contaminated with aflatoxins. The results of positive samples are given in Table 2.

Table 2. Positive samples were triplicated; results showed the concentration of $\mathrm{AFB}_{1}$ contamination in red Chillies, black pepper, Figs and dried apricots.

\begin{tabular}{lllll}
\hline $\begin{array}{l}\text { Sample } \\
\text { Number }\end{array}$ & $\begin{array}{l}1 \\
\text { Aflatoxin B } \\
\mu \mathrm{gkg}^{-1}\end{array}$ & $\begin{array}{l}2 \\
\text { Aflatoxin B } \\
\mu \mathrm{gg}^{-1}\end{array}$ & $\begin{array}{l}3 \\
\text { Aflatoxin B }_{1} \\
\mu \mathrm{gkg}^{-1}\end{array}$ & $\begin{array}{l}\text { Aflatoxin B } \\
\text { Average }_{1} \\
\mu \mathrm{gkg}^{-1}\end{array}$ \\
\hline Chilli A & 68.08 & 68.87 & 68.34 & $68.43 \pm 0.40$ \\
Chilli D & 24.12 & 23.86 & 24.01 & $23.99 \pm 0.13$ \\
Chilli G & 39.04 & 39.55 & 39.87 & $39.49 \pm 0.42$ \\
Chilli I & 96.98 & 97.71 & 97.56 & $97.42 \pm 0.38$ \\
Chilli K & 63.51 & 63.91 & 63.03 & $63.48 \pm 0.44$ \\
Chilli N & 69.45 & 69.94 & 69.25 & $69.54 \pm 0.35$ \\
Chilli O & 89.56 & 89 & 89.05 & $89.20 \pm 0.30$ \\
Chilli P & 59.22 & 59.46 & 59.64 & $59.44 \pm 0.21$ \\
Chilli R & 76.45 & 77.44 & 76.98 & $76.95 \pm 0.49$ \\
Chilli Z & 71 & 70.95 & 71.45 & $71.13 \pm 0.27$ \\
Chilli BB & 77.89 & 78.03 & 77 & $77.64 \pm 0.55$ \\
Pepper O & 47.3 & 47.72 & 48.02 & $47.68 \pm 0.36$ \\
Pepper T & 76.01 & 75.73 & 75.6 & $75.78 \pm 0.21$ \\
Pepper U & 53.48 & 53.56 & 53.24 & $53.42 \pm 0.16$ \\
Pepper V & 63.89 & 64.93 & 64.5 & $64.44 \pm 0.52$ \\
Fig A & 11.56 & 11.89 & 11.2 & $11.55 \pm 0.34$ \\
Fig B & 13.56 & 13.93 & 13.01 & $13.51 \pm 0.46$ \\
Fig E & 14.32 & 14.73 & 14.25 & $14.43 \pm 0.25$ \\
Fig F & 9.6 & 9.59 & 9.35 & $9.51 \pm 0.14$ \\
Fig K & 9.58 & 9.29 & 9.78 & $9.55 \pm 0.24$ \\
Fig L & 8.34 & 8.63 & 8.78 & $8.58 \pm 0.22$ \\
Fig S & 9.68 & 9.26 & 9.43 & $9.45 \pm 0.21$ \\
Fig T & 6.87 & 6.85 & 6.45 & $6.72 \pm 0.23$ \\
Apricot T & 12.89 & 13.26 & 13.45 & $13.2 \pm 0.28$ \\
\hline & & & &
\end{tabular}

The results in present study depicted that figs samples showed contamination ranging between $6.72-14.43 \mu \mathrm{gkg}^{-1}$ and merely one sample of dried apricots was contaminated with aflatoxin $B_{1}$. Aflatoxin $B_{1}$ detected in sample of apricot was $13.2 \mu \mathrm{gkg}^{-1}$ exceeding the USFDA permissible levels. The range of aflatoxin contamination in red chillies was 23.99-97.42 $\mu \mathrm{gkg}^{-1} .9$ chili samples were exceeding permissible levels set by UNCTAD and 2 were within the permissible levels. $97.42 \mu \mathrm{gkg}^{-1}$ in red chili sample was the highest amount of aflatoxin which was beyond the set regulations. According to WHO (World Health Organization) the recommended aflatoxins level for red chilli is $30 \mu \mathrm{gkg}^{-1}$ [14]. As aflatoxins are toxic secondary metabolites so their detection in different food commodities like dried fruits and spices is very important [15]. The results are given in Fig. 1. 


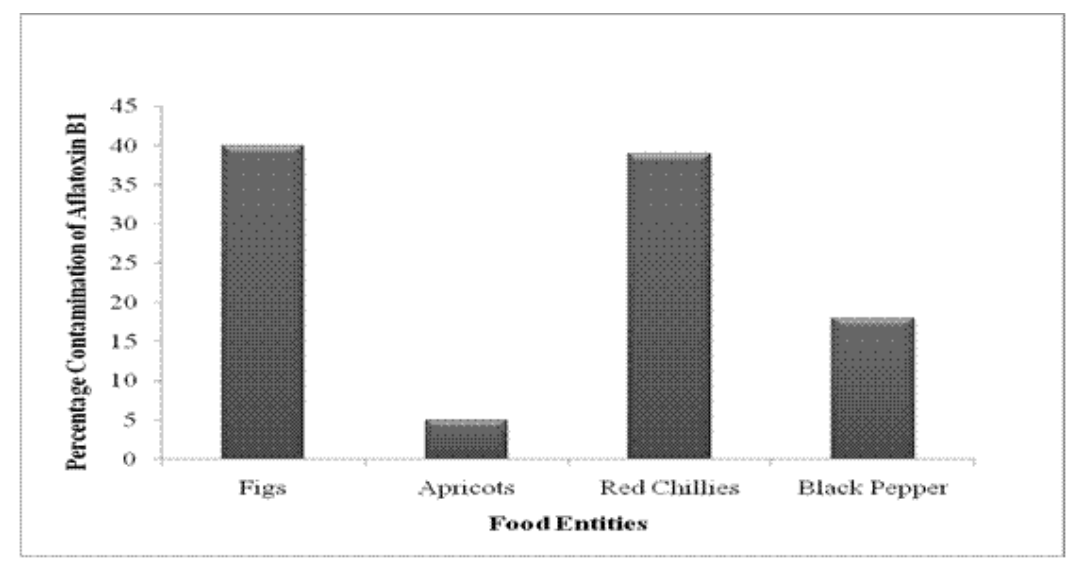

Fig. 1. Overall Aflatoxin contamination in different food commodities.

\section{Conclusion}

It was concluded from above study that the percentage of aflatoxin contamination in selected food commodities is low i.e. 26\%. Only 24 out of 90 samples showed the presence of Aflatoxin $\mathrm{B}_{1}$. But this is an alarming condition because regular intake of food contaminated with aflatoxins may cause cruel health damage to the consumers. As spices and dried fruits are vital parts of human diet and may badly affect by aflatoxins contamination; so these food commodities should be tackled with care in order to avoid aflatoxins contamination. The authorities in Pakistan should check and implement regulations strictly to monitor the food samples for aflatoxins contamination in food commodities on regular basis to save public health. There should be proper measures while harvesting, collecting, transporting, drying and storing food entities. It is suggested for consumers to buy spices, dried fruits and other food items from authentic and trustworthy retailers.

\section{References}

1. R. Stanisławczyk, M. Rudy, and B. Świątek, NaukaPrzyroda Technol. 7, 16 (2013).

2. S. Ahsan, I. A. Bhatti, M. R. Asi, H. N. Bhatti, and M. A. Sheikh, Int. J. Agric. Biol. 12, 571 (2010).

3. IARC, Monographs on the Evaluation of Carcinogenic Risks to Human, Some Traditional Herbal Medicine, Some Mycotoxins, Naphthalene and Styrene, No. 82. (Lyon, France, 2003).

4. D. Bhatnagar, K. C. Ehrlich, and T. E. Cleveland, App. Microbiol. Biotechnol. 61,83 (2003).https://doi.org/10.1007/s00253-002-1199-x

5. D. Lerda, Mycotoxin Fact Sheet, $3^{\text {rd }}$ Edition, JRC Technical Notes, IRRM (Geel Belgium, 2010).

6. M. A. Asghar, E. Zahir, S. Rantilal, A. Ahmed, and J. Iqbal, Food Addit. Contam. 9, 113 (2016).https://doi.org/10.1080/19393210.2016.1150356

7. A. Nisa, N. Zahra, and S. Hina, Bangl. J. Sci. Ind. Res. 49,189 (2015). https://doi.org/10.3329/bjsir.v49i3.22134 
8. P. Karlovsky, M. Suman, F. Berthiller, J. De Meester, G. Eisenbrand, I. Perrin, I. P. Oswald, G. Speijers, A. Chiodini, T. Recker, and P. Dussort, Myco. Res. 32, 179 (2016).

9. M. H. Iha and M. W. Trucksess, Food Addit. Contam. 27, 1142

(2010).https://doi.org/10.1080/19440041003795319

10. A. Nisa, N. Zahra, S. Firdous, N. Ejaz, and S. Hina, Pak. J. Sci. Ind. Res. 55, 27 (2012).

11. UNCTAD/Commonwealth Secretariat, the Global Spice Trade and the Uruguay Round Agreements (Geneva and London: UNCTAD, and Commonwealth Secretariat, 1996).

12. M. Saquib, A Study of the Impact of Environmental Requirements on India's Export Performance and the Scoping Study for Environmentally Friendly Products, FAO, Mycotoxin Prevention and Control in Food grains-Aflatoxin Research on Grain in Asia, UNCTAD (2000).

13. S. V. Reddy, M. D. Kiran, R. M. Uma, D. K. Thirumala, and D. V. R. Reddy, Food Addit. Contam. 18, 553 (2001).https://doi.org/10.1080/02652030119491

14. R. K. Sharma and S. Parisi, Aflatoxins in Indian Food Products: Toxins and Contaminants in Indian Food Products (Springer, Cham, 2017) pp. 13-24. https://doi.org/10.1007/978-3-319-48049-7

15. N. P. Gurav and S. Medhe, Anal. Chem. Ind. J. 17, 126 (2018). 